(2) Open Access Full Text Article

REVIEW

\title{
Assessing the relationship between obesity and asthma in adolescent patients: a review
}

This article was published in the following Dove Press journal:

Adolescent Health, Medicine and Therapeutics

16 February 2013

Number of times this article has been viewed

\author{
Kristie R Ross \\ Meeghan A Hart \\ Department of Pediatrics, Rainbow \\ Babies and Children's Hospital and \\ Case Western Reserve University \\ School of Medicine, Cleveland, $\mathrm{OH}$, \\ USA
}

Correspondence: Kristie R Ross

Case Western Reserve University,

Rainbow Babies and Children's Hospital,

I I 00 Euclid Avenue, Cleveland,

$\mathrm{OH} 44106$, USA

Tel +I 2168443267

Fax + 2168445916

Email kristie.ross@uhhospitals.org

\begin{abstract}
The parallel rise in the prevalence of obesity and asthma over the last several decades has led to an extensive line of investigation into the relationship between these two conditions. This review will discuss evidence from laboratory-based studies, observational clinical studies, and clinical trials that suggests that obesity adversely influences asthma through multiple mechanisms. The effect of obesity on asthma during adolescence, including asthma incidence, the severity and control of existing asthma, lung function, and exacerbations, will be reviewed.
\end{abstract}

Keywords: children, airway reactivity

\section{Introduction}

Asthma and obesity are two of the most common conditions of childhood and adolescence. Adolescence is a time of rapid growth and hormonal shifts, as well as changes in health behaviors. These changes likely play a role in chronic illnesses, including asthma and obesity. This review highlights studies that examine the relationship between obesity and asthma during adolescence.

\section{Epidemiology of asthma and obesity}

Asthma is a heterogeneous syndrome characterized by airway hyper-reactivity, airway inflammation, and episodes of coughing, wheezing, and shortness of breath that resolve spontaneously or with bronchodilators. The prevalence of asthma has increased worldwide during the last several decades, particularly in developed countries. ${ }^{1}$ Among US children aged 17 years and younger, the prevalence of asthma in 2009 was nearly 1 in $10 .^{2}$ Prevalence rates may be twice as high in poor and minority populations. ${ }^{3}$ Prior to puberty, asthma is more common and more severe in boys; after puberty, asthma is more common and more severe in women. ${ }^{2,4}$ Although genetic predisposition plays an important role in the development of allergy and asthma, ${ }^{5}$ the etiology of asthma is complex. It most likely is determined by multiple interacting genetic and environmental factors. Well-established risk factors for asthma include male sex, race, allergic rhinitis, atopic dermatitis, family history of atopy, viral lower respiratory tract infections early in life, and exposure to indoor and outdoor air pollution.

A parallel rise in the prevalence of childhood obesity during the same time period has led to speculation that in addition to these classic risk factors, obesity may explain some of the increased burden of asthma. It is important to note that obesity in childhood may be defined in several ways. The most commonly used measurement is body mass 
index (BMI), calculated as weight/height ${ }^{2}$. In adults, a BMI of at least $30 \mathrm{~kg} / \mathrm{m}^{2}$ is considered obese. Lean body mass and normal body mass indices change throughout childhood, so definitions of overweight and obesity in children are based on age and sex-specific percentiles or z-scores. Using the US Centers for Disease Control growth charts, in children aged 2-20 years, overweight is defined as a BMI between the 85 th and 95th percentile for age and sex, and obesity as a BMI at or above the 95th percentile for age and sex. Additional measures of obesity less commonly used in children include waist circumference, percentage body fat, and waist/hip ratio or other measures of central obesity.

According to the National Center for Health Statistics, the prevalence of obesity in US children increased from $4 \%$ in 1971-1974 to 17\% in 2003-2006 for children aged 6-11 years, and from $6 \%$ to $17.6 \%$ for children aged 12-19 years during the same time periods. ${ }^{6}$ Data from the National Health and Nutrition Examination Survey (NHANES) (2009-2010), in which a probability sample of US children were interviewed and examined, including standardized measurement of height and weight, suggest that the current prevalence of overweight (BMI $\geq 85$ th percentile) among US adolescents is $33.6 \%$ (95\% confidence interval [CI] 30.9\%-36.5\%) and obesity (BMI $\geq 95 \%$ percentile) is $18.4 \%(95 \%$ CI $15.8 \%-21.3 \%) .^{7}$ As with asthma, the prevalence of obesity is substantially higher in poor and minority children. Obesity prevalence is $23.7 \%$ (95\% CI $19.2 \%-9.0 \%$ ) in non-Hispanic black adolescents and $23.3 \%$ (95\% CI 18.2\%-30.6\%) in Hispanic adolescents. ${ }^{7}$

Obesity may adversely affect asthma inception, severity, and response to therapy. There is mounting evidence that childhood obesity is a risk factor for the development of asthma, including cross-sectional and prospective studies. ${ }^{8-11}$ Recent studies have also suggested that obese asthmatics respond differently to standard therapies than their nonobese counterparts, with increased symptom burden and increased or prolonged exacerbations. ${ }^{12,13}$ The focus of this review is on the impact of obesity on asthma during adolescence. We searched MedLine using the keywords "asthma," "obesity," "adolescence," and "lung function" to identify studies to be included in this review, focusing on studies published in English since 2000.

\section{Role of obesity in asthma inception in late childhood and adolescence (summarized in Table I)}

Multiple cross-sectional and prospective studies have demonstrated that childhood obesity is a risk factor for the development of asthma. ${ }^{8-11}$ Although some have proposed that reduced physical activity due to asthma leads to obesity, thus explaining the associations seen in cross-sectional studies, there are now extensive data suggesting that increased BMI precedes the development of asthma. ${ }^{14} \mathrm{~A}$ meta-analysis published in 2006 found that both high birth weight and overweight or obesity during mid-childhood were associated with increased risk of asthma later in childhood or during adolescence (relative risk 1.2, 95\% CI 1.1-1.3, for high birth weight and relative risk 1.5, 95\% CI 1.2-1.8, for childhood obesity). ${ }^{15}$ In the Tucson Children's Respiratory Study, a longitudinal birth cohort of over 1200 children who have been followed for several decades, girls who became overweight or obese between 6 and 11 years of age were more likely to develop new infrequent or frequent wheezing than those who did not become overweight or obese (odds ratio [OR] 6.8, 95\% CI 2.4-19.4, and 5.5, 95\% CI 1.3-23.3, respectively). No such relationship was found in boys. ${ }^{10}$ In subsequent analyses of the same birth cohort, obesity and early onset of puberty were independent predictors of persistence of wheezing and asthma beyond puberty with no effect modification by sex. ${ }^{16}$ In another longitudinal prospective study, the Children's Health Study, over 3700 4th, 7th, and 10th grade children without asthma were recruited from public schools in Southern California and followed annually until high school graduation. Overweight and obesity were associated with an increased risk of a new physician diagnosis of asthma during the study, with a stronger relationship seen in boys than in girls, and in nonallergic than in allergic children. ${ }^{17}$ In a more recent study conducted in Taiwan, over 4000 adolescents with asthma-like symptoms but no formal diagnosis of asthma were followed for 1 year. Further evaluation, including pulmonary function testing, was conducted in order to determine whether the children met formal diagnostic criteria for asthma. Overweight and obesity at enrollment increased the odds of asthma being diagnosed in girls but not in boys. ${ }^{18}$ Weight change during the 1-year study was not associated with an increased risk of asthma in either sex.

Differences in age and other inclusion criteria may explain the differences seen across studies in the effect of sex on the relationship between obesity and incident asthma. Though not well understood, there are clear and dramatic changes in asthma epidemiology at the time of puberty. Prior to puberty, asthma is more common and more severe in boys; after puberty, asthma is more common and more severe in women. ${ }^{2,4}$ Obesity appears to influence pubertal timing differently in boys than in girls. ${ }^{19}$ Given these complex 


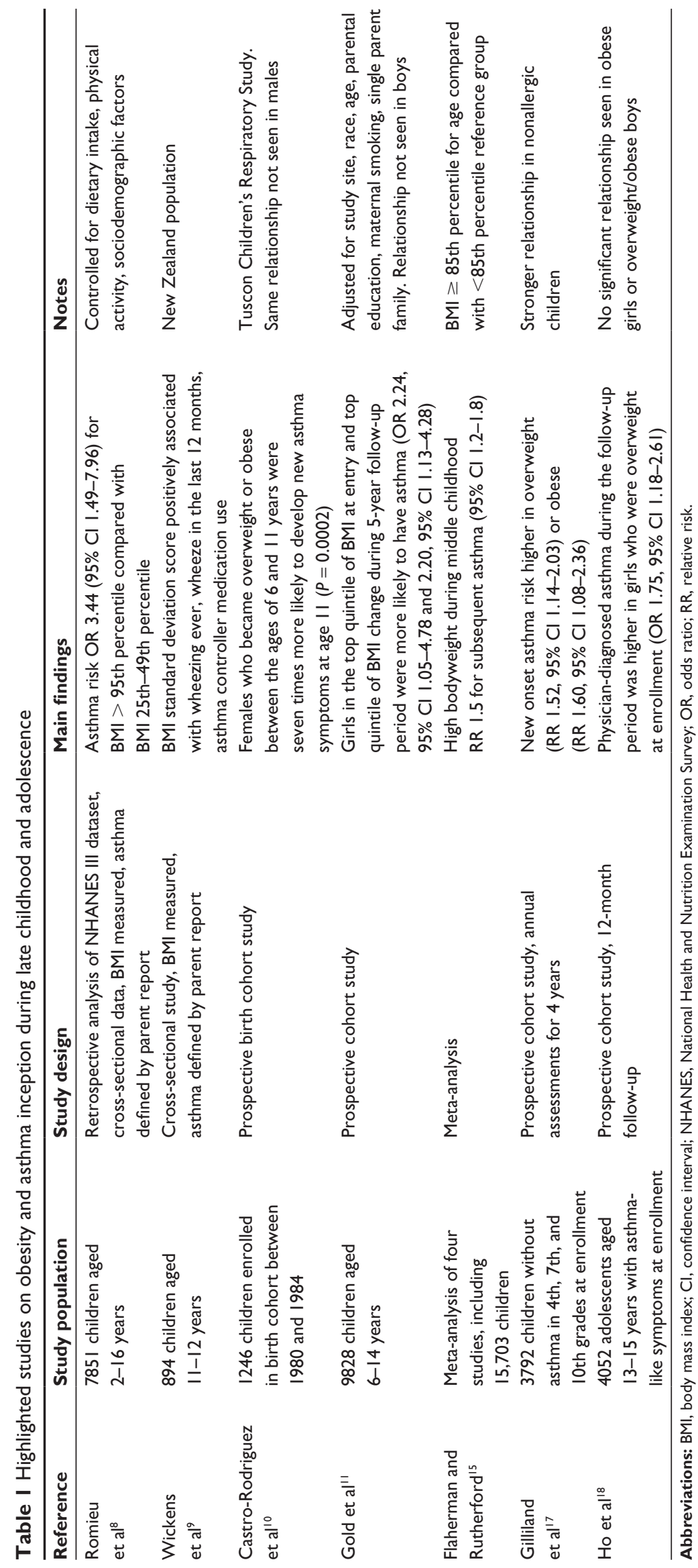


relationships, it seems important that studies examining the relationship between obesity and asthma during adolescence include some assessment of, and adjustment for, pubertal status. Of the studies discussed, the Tucson Children's Health Study was the only study to include this type of assessment. ${ }^{16}$ The findings by Castro-Rodriguez et $\mathrm{al}^{10}$ about sex-specific effects of obesity on incident asthma after age 11 years are consistent with data on sex-specific effects of obesity on asthma in adults..$^{20,21}$

In summary, there is substantial evidence that obesity is a risk factor for the development of asthma, although this relationship appears to be more consistent in females than in males. The next several sections explore the relationship between obesity and the burden of asthma once it is established. There are multiple asthma outcomes important to children, their families, clinicians, and researchers, including lung function, exacerbations, symptom burden, and response to therapies.

\section{Obesity and lung function (summarized in Table 2)}

Lung function measurements typically reported in children with asthma include forced expiratory volume in 1 second $\left(\mathrm{FEV}_{1}\right)$, forced vital capacity $(\mathrm{FVC})$, and the ratio of these two measurements $\left(\mathrm{FEV}_{1} / \mathrm{FVC}\right)$. Because lung volumes vary with age, sex, and height, $\mathrm{FEV}_{1}$ and $\mathrm{FVC}$ are generally reported as percent predicted values based on nomograms of healthy children. In obstructive lung diseases such as asthma, the volume of air that can be exhaled quickly from the lungs is reduced out of proportion to the total volume that can be exhaled, resulting in a reduced $\mathrm{FEV}_{1} / \mathrm{FVC}$ ratio. Children with asthma often have normal $\mathrm{FEV}_{1}$ and FVC in between exacerbations, although there may be evidence of airway obstruction with $\mathrm{FEV}_{1} / \mathrm{FVC}$ ratios below 0.8 . The data on the influence of obesity on lung function in children are somewhat conflicting. Researchers analyzed data from the Childhood Asthma Management Program (over 1000 children aged 5-12 years with asthma) to determine the effect of BMI on lung function. They found that increasing $\mathrm{BMI}$ was associated with increasing $\mathrm{FEV}_{1}$ and $\mathrm{FVC}$ percent predicted, but reduced $\mathrm{FEV}_{1} / \mathrm{FVC}$ ratios were suggestive of airway obstruction. ${ }^{22}$ Among primarily minority adolescents aged 12-20 years with asthma participating in the Inner City Asthma Consortium's Asthma Control Evaluation study, increasing BMI was associated with increasing $\mathrm{FEV}_{1}$ percent predicted among boys but not girls, and was associated with reduced $\mathrm{FEV}_{1} / \mathrm{FVC}$ ratios in both sexes. ${ }^{23}$ Because high BMI may reflect both increased fat and lean body mass,

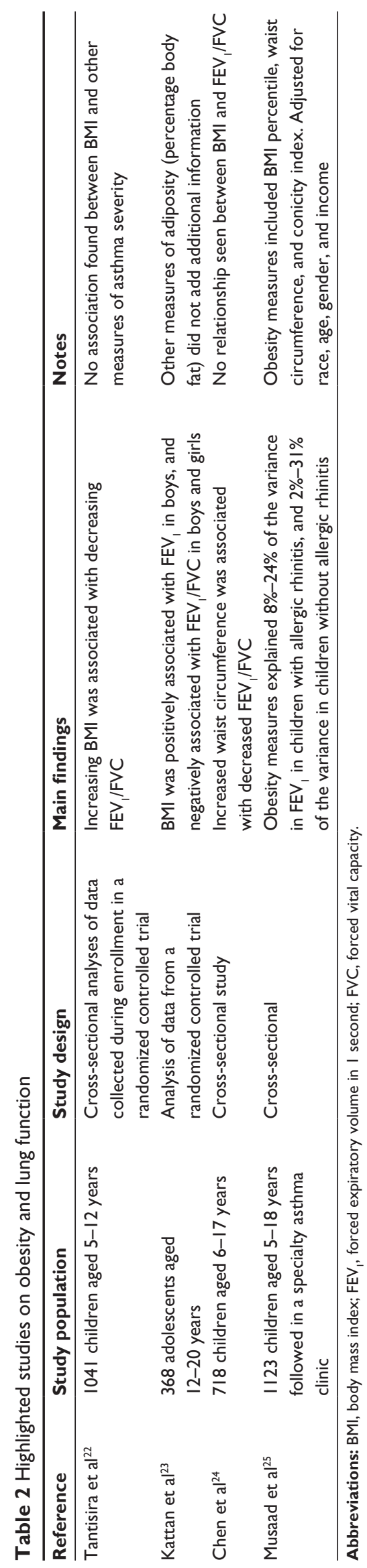


investigators in this study also measured percent body fat using dual-energy X-ray absorptiometry scans. Increasing percent body fat was associated with reduced $\mathrm{FEV}_{1} / \mathrm{FVC}$ ratio in both sexes but reached statistical significance only in boys. In a separate study of 718 primarily Caucasian children aged 6-17 years, waist circumference but not BMI was associated with a decline in $\mathrm{FEV}_{1} / \mathrm{FVC} .{ }^{24}$ Others found waist circumference to be negatively associated with mean $\mathrm{FEV}_{1}$, whereas $\mathrm{BMI}$ was positively associated with $\mathrm{FEV}_{1}{ }^{25}$

In summary, the data on the effect of obesity on lung function are conflicting, but the most consistent finding is that obesity is associated with airway obstruction (reduced $\mathrm{FEV}_{1} / \mathrm{FVC}$ ).

\section{Obesity and exacerbations (summarized in Table 3)}

Exacerbations remain a common and troubling component of pediatric asthma, despite the availability of medications to control symptoms, with over half of children with asthma reporting an asthma attack in the previous year and nearly one-third reporting seeking urgent care or emergency department (ED) treatment for an attack. ${ }^{26}$ Exacerbations are not always related to underlying asthma severity or control. A lack of consensus on the definition of an asthma exacerbation makes comparing studies examining the effect of obesity on exacerbations difficult, but most researchers and recently published guidelines agree that the need for systemic corticosteroids is a reasonable definition. ${ }^{27}$ Using this definition, several studies suggest that obesity is associated with an increased risk of asthma exacerbations in children and adolescents. In an analysis of insurance claims data from more than 30,000 children aged 5-17 years with asthma in Southern California, investigators asked whether overweight and obesity were associated with several markers of asthma severity, including the use of oral corticosteroids, after adjusting for multiple confounders, including demographic variables, parental education, asthma controller medication use, and comorbid gastroesophageal reflux disease and diabetes mellitus. ${ }^{28}$ Children who were overweight and obese were more than $20 \%$ more likely to have been prescribed an oral corticosteroid than the reference population (adjusted OR $1.21,95 \%$ CI 1.13-1.29, and adjusted OR 1.28, 95\% CI $1.21-1.36$, respectively). In a separate study of 368 primarily minority children aged 12-20 years, adolescent females who were overweight were nearly 2.5 times more likely than their normal weight peers to have an exacerbation during a 1-year clinical trial where asthma management was optimized using published guidelines (OR 2.49, 95\% CI 1.25-5.14). ${ }^{23}$

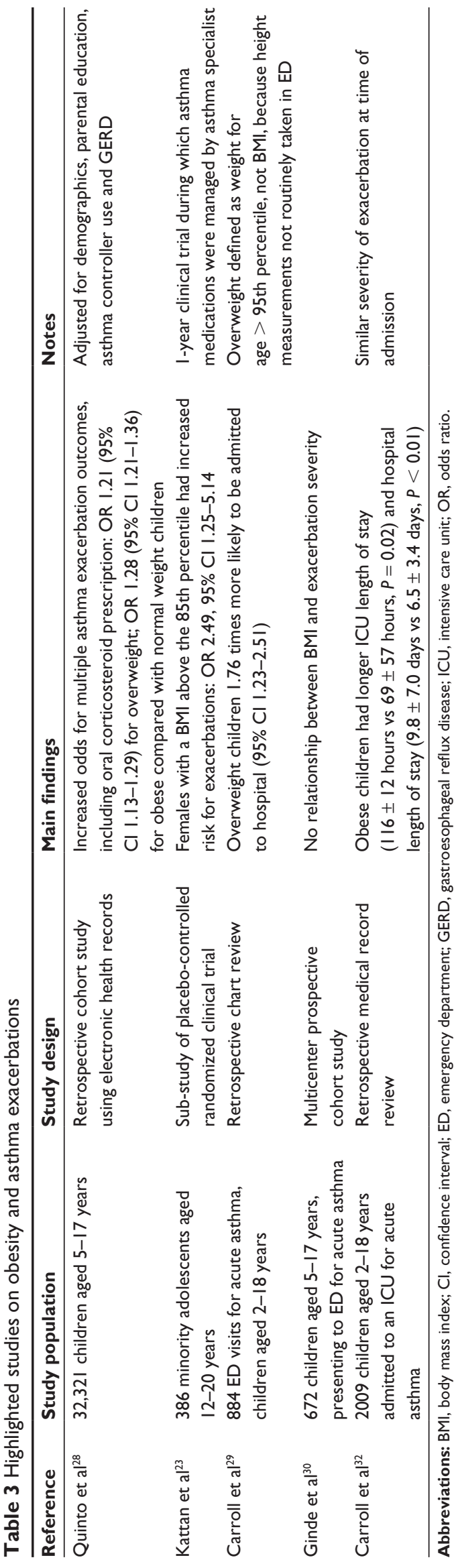


More severe asthma exacerbations require hospitalization. In a retrospective analysis of all children aged 2-18 years who were evaluated in an ED of a children's hospital in 2005, investigators examined whether children with a weight for age $>95$ th percentile for age and sex (overweight) were more likely to require hospital admission than those with a weight for age $\leq$ 95th percentile (nonoverweight) after adjusting for age, race/ethnicity, sex, and poverty status..$^{29} \mathrm{BMI}$ was not used to define adiposity, due to the retrospective nature of the study and lack of routine height measurements in the ED setting. Severity at presentation was assessed using a modified pulmonary index score. In the 884 visits to the ED included, overweight was not associated with differences in severity at presentation, but, in adjusted analyses, overweight children were 1.76 times more likely to be admitted (95\% CI 1.23-2.51) than their nonoverweight peers. Analysis from a prospective study conducted in 44 EDs from 1997 to 1998 failed to find an association between BMI and asthma admission rates among the 672 participants aged 5-17 years, although obesity prevalence was more common among children presenting to the ED for asthma compared with the general population. ${ }^{30}$ Obesity has been associated with higher complication rates in the intensive care unit for multiple conditions. ${ }^{31}$ Specific to asthma, children with asthma who required intensive care unit treatment and were obese had significantly longer intensive care unit and hospital lengths of stay than their nonobese peers, despite a similar severity of illness at presentation. ${ }^{32}$

In summary, obesity is associated with asthma exacerbations and severity of exacerbations in many, though not all, published studies.

\section{Obesity and asthma severity and control (summarized in Table 4)}

Asthma severity and control are important, yet confusing, concepts whose definitions have changed over the last several decades and that may be defined differently by different authors. When possible, the discussion of the effect of obesity on asthma severity and control to follow will use these terms as defined by international guidelines, not necessarily as defined by study authors. According to international guidelines, including those of the Global Initiative for Asthma and the National Heart, Lung, and Blood Institute, asthma severity is determined by the level of symptoms and lung function measures in children with untreated asthma, or the intensity of treatment required to achieve control. ${ }^{33,34}$ Guidelines also suggest that once the diagnosis of asthma is established and treatment is initiated, achieving asthma

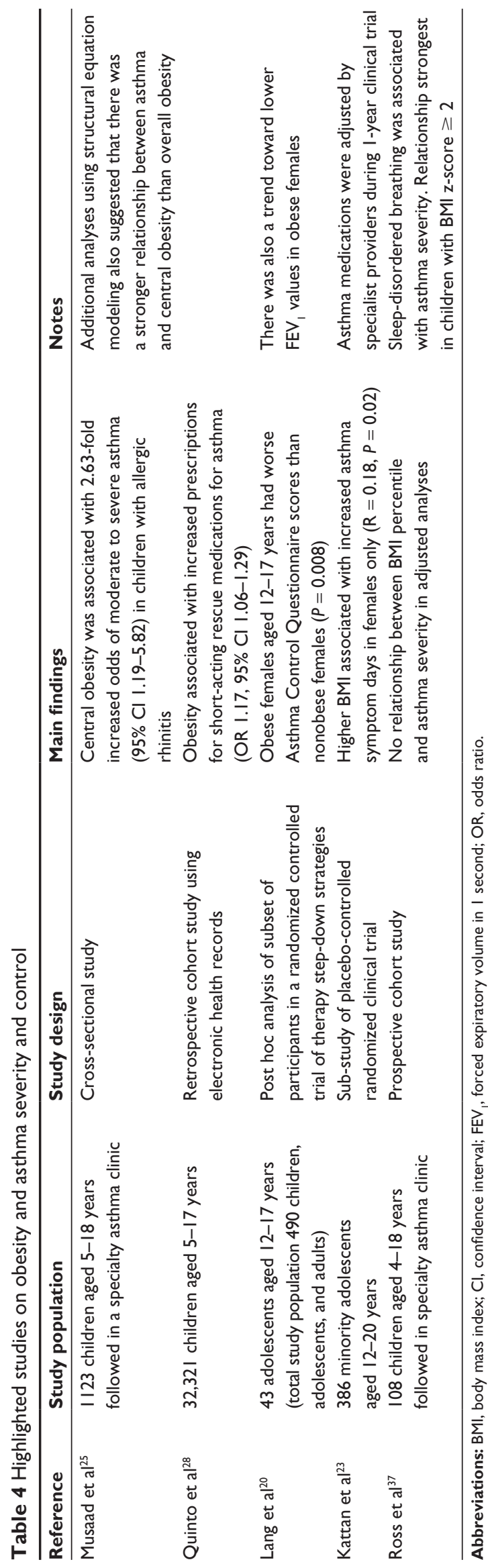


control should be the focus of care. ${ }^{33,34}$ Asthma control refers to the symptom burden experienced by patients, as well as the risk of future deterioration, including exacerbations, lung function decline, and side effects of medications. Studies in children and adolescents suggest that obesity may adversely influence both asthma severity and control.

In a cross-sectional case control study of over 1100 children aged 5-18 years recruited from a single outpatient allergy/immunology clinic, investigators asked whether obesity was associated with allergic asthma in children. ${ }^{25}$ They were specifically interested in whether the distribution of obesity was important in the relationship between obesity and asthma diagnosis, lung function, and symptom burden. The authors classified asthma severity using symptom burden and lung function, but it is unclear whether these children were treated with asthma controller therapy or not. Central obesity, determined using the conicity index, a calculation that evaluates waist circumference in relation to height and weight, was associated with asthma severity, whereas there was no association with BMI. They found that in children with allergic rhinitis, moderate to severe asthma was 2.63 times more likely in children in the highest strata of conicity index (95\% CI 1.19-5.82) than in the lowest strata.

In a large cohort study of asthma in children and adults conducted by the American Lung Association Asthma Clinical Research Centers, the influence of obesity on asthma symptoms was strongest in adolescent girls. ${ }^{20}$ Obese girls aged 12-17 years, but not boys, exhibited worse scores on the validated Asthma Control Questionnaire and modified Asthma Control Questionnaire compared with their nonobese peers. Findings were similar whether lung function data were included in the questionnaire or not (modified version). Although a high proportion of participants in the study were on at least one asthma controller therapy, investigators did not report whether obese and nonobese participants had similar rates of asthma controller therapies prescribed. It is therefore difficult to determine whether the differences in obese and nonobese adolescent girls reflect differences in treatment or response to treatment.

Using a large insurance claims database of over 30,000 children and adolescents with asthma, investigators in Southern California found a relationship between obesity and increased use of quick-relief inhalers, suggesting that obesity was associated with more asthma symptoms or worse asthma control. ${ }^{28}$ Children who were obese were 1.17 times more likely to be dispensed six or more quick-relief inhalers per year than their nonobese peers, after adjusting for age, gender, race, parental education level, asthma controller use, and diagnosis of gastroesophageal reflux disease and diabetes mellitus.

Although cross-sectional studies can be helpful, asthma severity and control assessments are probably more accurate in longitudinal analyses, because asthma symptoms are, by definition, intermittent and seasonal. The Asthma Control Evaluation Study was a randomized clinical trial of inner-city adolescents aged $12-20$ years designed to determine whether measurement of exhaled nitric oxide in addition to providing guidelines-based care improved asthma outcomes above guidelines-based care alone. ${ }^{35} \mathrm{~A}$ sub-study of the Asthma Control Evaluation Study sought to understand the influence of obesity on asthma control in this population. ${ }^{23}$ Participants received expert guidelines-based algorithm-driven care throughout the 1-year study, allowing investigators to conduct a more rigorous assessment of the influence of obesity on asthma symptoms while controlling for asthma treatments. Higher BMI was associated with increased asthma symptoms days (worse asthma control) in female adolescents only $(\mathrm{R}=0.18, P=0.02)$.

Although outside the context of a clinical trial, we examined the relationship between adiposity and asthma severity using a composite measure of symptoms, level of controller therapy prescribed, and health care utilization in a cross-sectional analysis ${ }^{36}$ and over a 1-year period during which asthma was treated by specialists according to national guidelines. ${ }^{37}$ Obesity was highly prevalent in the population but was not associated with asthma control at baseline or asthma severity after 1 year of follow-up and treatment. However, sleep-disordered breathing (SDB) was strongly associated with severe asthma (OR 3.62, 95\% CI 1.26-10.40), with much of this relationship driven by children with a BMI z-score of 2 or higher.

In summary, there are data to suggest that obesity influences asthma severity and control, although there are inconsistencies in the literature. Some of these inconsistencies may be due to sex differences, varied definitions of asthma severity and control, whether or not patterns of obesity were included (ie, central fat deposition), and inclusion of appropriate confounding variables such as comorbidities.

\section{Weight loss effects}

Studies of obese adults with asthma have demonstrated that weight loss results in improved or resolved asthma, including improvement in multiple measures of lung function, ${ }^{38-41}$ improvement in asthma control and rescue medication use,$^{39-41}$ reduction in dose or withdrawal of controller medications ${ }^{42}$ reduced exacerbation rates,${ }^{40}$ and improvement 
in quality of life measures. ${ }^{43}$ The effects on objective measures, particularly pulmonary function, provide evidence that the effects of weight loss on asthma are not solely due to improved conditioning and reduced symptom perception. Only a single clinical trial evaluating the effect of weight loss on asthma outcomes in children has been published. ${ }^{44}$ Of the 76 participants (mean age $17 \pm 1.4$ years) who completed a 1-year multidisciplinary weight loss intervention, 20 had asthma diagnosed by a pulmonologist based on symptoms, medication use and response, and demonstration of reversible airflow limitation on lung function testing. This rigorous definition of asthma addresses some of the concerns about misclassification bias in studies of adults. Adolescents with and without asthma had improvement in lung function following weight loss, but those with asthma had a significant reduction in wheeze and cough compared with those without asthma. Asthma severity was classified according to previous Global Initiative for Asthma guidelines as moderate persistent, mild persistent, and intermittent. Using this classification system, the proportion of participants with asthma classified as intermittent increased from $27 \%$ to $81 \%$ after the 1 -year intervention $(P<0.05)$. Further larger studies confirming these findings in adolescents and younger children will be necessary, but they are reassuring that the evidence from studies in adults that weight management is an effective adjunctive therapy for asthma is also true in children.

\section{Hypothesized mechanisms linking obesity and asthma}

The mechanisms by which obesity adversely influences asthma prevalence and morbidity are not well understood, but several theories have been proposed (see Table 5) (reviewed elsewhere). ${ }^{45}$ These include the mechanical effects of obesity on airway physiology, chronic systemic inflammation and oxidative stress, alterations in adipokines that are also important in immune regulation, and shared comorbidities, including SDB and gastroesophageal reflux disease.

Table 5 Hypothesized mechanisms linking obesity and asthma

\begin{tabular}{ll}
\hline $\begin{array}{l}\text { Hypothesized mechanisms linking obesity } \\
\text { and asthma }\end{array}$ & $\begin{array}{l}\text { Selected } \\
\text { references }\end{array}$ \\
\hline $\begin{array}{l}\text { Mechanical effects of obesity on airway physiology } \\
\text { Shared inflammatory signaling abnormalities }\end{array}$ & 46,47 \\
Shared alterations in oxidative/antioxidant signaling & $48-56$ \\
Effect of adipokines on airway biology and immune & 57,58 \\
regulation & $52,64-67$ \\
Altered metabolic signaling & $59-63$ \\
Comorbid conditions, including sleep-disordered & $36,37,68-73$ \\
breathing and gastroesophageal reflux disease & \\
\hline
\end{tabular}

In respect of mechanical effects on the lung, obesity is associated with reduced functional residual capacity and lower tidal volumes, resulting in reduced stretch of airway smooth muscle. Stretch is an important bronchodilator, so reduced stretch due to lower tidal volumes may result in stiffer airway smooth muscle. ${ }^{46}$ In adults, the combination of obesity and asthma is associated with loss of the normal bronchodilatory response to a deep breath compared with subjects with asthma or obesity alone. ${ }^{47}$

Obesity is also associated with systemic inflammation, including higher C-reactive protein (CRP), interleukin-6, and tumor necrosis factor- $\alpha$, which may adversely influence asthma and airway inflammation. ${ }^{4-52}$ Obesity and elevated CRP were associated with asthma severity in multivariable analysis of NHANES data from 2001 to 2004, with children with elevated CRP levels having 1.33 increased odds of having severe asthma $(P<0.001) .{ }^{53}$ Some studies suggest that there is a distinct asthma-obesity phenotype, with unique pathophysiology and inflammatory signaling. Pediatric asthma is generally thought to be characterized by $\mathrm{T}$ helper type 2 (Th2) or allergic-type inflammation. However, there are data to suggest that the asthma phenotype seen in association with obesity is associated with Th1-type inflammation, ${ }^{54}$ which may explain clinical studies that have found obesityassociated asthma to be relatively resistant to classic asthma therapies that target Th2-type inflammation. ${ }^{13,55,56}$ Obesity and asthma are both characterized by higher than normal levels of oxidative stress, and this shared abnormal signaling may partly explain the interaction between these two conditions (reviewed elsewhere).$^{57}$ This hypothesis is supported by findings in adults with both obesity and asthma that weight loss due to caloric restriction was associated with improvements in measures of oxidative stress, lung function, and asthma symptoms. ${ }^{58}$

Even in childhood, obesity is associated with metabolic syndrome, a cluster of abnormalities that includes visceral adiposity and abnormalities in glucose and lipid regulation. Metabolic syndrome is a risk factor for future cardiovascular morbidity in both adults and children. ${ }^{59,60}$ Whether the presence of metabolic syndrome or its components is important in mediating the relationship between obesity and airway disease is not yet known, but there are a few studies that suggest that it might be. In a recent cross-sectional study of adults, metabolic syndrome and abdominal obesity were associated with lung function impairment independent of BMI. ${ }^{61}$ Insulin resistance was identified as a risk factor for asthma in a population-based study and in a cohort of obese children in a weight management program. ${ }^{62,63}$ The key to 
this relationship may be in alterations in the adipose tissue hormone adiponectin. Glucose and insulin regulation are tightly linked to adiponectin. In contrast to other adipokines, adiponectin enhances sensitivity to insulin and has anti-inflammatory effects. Adiponectin levels decrease as fat mass increases, and reduced adiponectin is correlated with visceral adiposity and predicts the development of metabolic syndrome and type 2 diabetes.

There is also evidence for a role for adiponectin in asthma. In an animal model of allergic asthma, exogenous administration of adiponectin prevented the development of airway reactivity and allergic airway inflammation. ${ }^{64}$ Increased adiposity is also associated with increased circulating levels of the adipokine leptin. Leptin regulates appetite but is also involved in regulating the proliferation, activation, and cytokine secretion of T lymphocytes, an important cell type in asthma. ${ }^{52}$ Leptin levels negatively correlate with lung function in adults and children independent of BMI, suggesting that obesity-related changes in leptin may influence asthma morbidity. ${ }^{65,66}$ Airway leptin levels appear to be altered in obese subjects with asthma as well, although the relationship between these alterations and airway inflammation and oxidative stress is less clear. ${ }^{67}$

Obesity may also influence asthma through comorbid conditions that affect airway mechanics or inflammatory signaling. SDB is characterized by snoring and intermittent upper airway obstruction and arousal from sleep, with more severe disease associated with intermittent hypoxia. Although there is some controversy about whether obesity is as clearly linked to SDB in children as it is in adults, ${ }^{68}$ studies have suggested that obesity is a significant risk factor for SDB in both younger children and adolescents, ${ }^{69}$ and that weight loss is an effective treatment. ${ }^{70,71}$ Oxidative stress and inflammation are associated with intermittent hypoxia and sleep disruption (reviewed elsewhere).$^{72}$ These alterations in signaling overlap with those seen in asthma and may, in part, be responsible for the findings in clinical studies that demonstrate that SDB is a risk factor for incident wheeze and asthma in young children and adversely affects asthma severity. ${ }^{37,73}$

\section{Limitations of this review}

This review is not meant to be a systematic review or metaanalysis. The studies included in this review use varied methodology and definitions of both obesity and asthma, contributing to the conflicting findings summarized here. As with all reviews on asthma, the definition of asthma, in particular, is variable from study to study. Most large epidemiologic studies define asthma by parent report of symptoms, medication use, or physician diagnosis of asthma. Clinical trials generally have more stringent criteria for defining asthma but rely heavily on parent report of prior diagnosis. Although most studies cited in this review define obesity using BMI percentile, only a few attempt to define the pattern of fat deposition. Central obesity is a phenotype that is important in the relationship between obesity and other inflammatory diseases such as heart disease and diabetes, and it may also be important in the relationship between asthma and obesity.

\section{Summary and future directions}

The parallel rise in the prevalence of obesity and asthma over the last several decades has led to an extensive line of investigation into the relationship between these two conditions. Evidence from laboratory-based studies, observational clinical studies, and clinical trials suggests that obesity adversely influences asthma through multiple mechanisms. Given some of the conflicting data reviewed here, it is important that future studies that are focused on the relationship between obesity and asthma during adolescence include assessments of pubertal status, and should include analyses of differential effects by sex and pattern of obesity. Current strategies for treating asthma in obese children do not include standardized weight management programs, but evidence from studies in adults and preliminary work in children suggest that this may be an effective adjunctive therapy. Given the breadth of data implicating obesity as a significant factor in asthma outcomes, future work should focus on developing and evaluating effective therapies targeting these often comorbid conditions.

\section{Disclosure}

The authors have no conflicts of interest related to this manuscript or the issues discussed in the manuscript.

\section{References}

1. Eder W, Ege MJ, von Mutius E. The asthma epidemic. $N$ Engl J Med. 2006;355(21):2226-2235

2. Akinbami L, Moorman J, Liu X. Asthma prevalence, health care use, and mortality: United States, 2005-2009. Natl Health Stat Report. 2011;32:1-14.

3. Webber MP, Carpiniello KE, Oruwariye T, Lo Y, Burton WB, Appel DK. Burden of asthma in inner-city elementary schoolchildren: do school-based health centers make a difference? Arch Pediatr Adolesc Med. 2003;157(2):125-129.

4. Moore WC, Bleecker ER, Curran-Everett D, et al. Characterization of the severe asthma phenotype by the National Heart, Lung, and Blood Institute's Severe Asthma Research Program. J Allergy Clin Immunol. 2007;119(2):405-413.

5. Duffy DL, Martin NG, Battistutta D, Hopper JL, Mathews JD Genetics of asthma and hay fever in Australian twins. Am Rev Respir Dis. 1990;142(6 Pt 1):1351-1358.

6. National Center for Health Statistics, Hyattsville, MD 2009. 
7. Ogden CL, Carroll MD, Kit BK, Flegal KM. Prevalence of obesity and trends in body mass index among US children and adolescents, 1999-2010. JAMA. 2012;307(5):483-490.

8. Romieu I, Mannino D, Redd S, McGeehin M. Dietary intake, physical activity, body mass index, and childhood asthma in the third national health and nutrition survey (NHANES III). Pediatr Pulmonol. 2004; 38(1):31-42.

9. Wickens K, Barry D, Friezema A, et al. Obesity and asthma in 11-12 year old New Zealand children in 1989 and 2000. Thorax. 2005;60(1):7-12.

10. Castro-Rodriguez JA, Holberg CJ, Morgan WJ, Wright AL, Martinez FD. Increased incidence of asthmalike symptoms in girls who become overweight or obese during the school years. Am J Respir Crit Care Med. 2001;163(6):1344-1349.

11. Gold DR, Damokosh AI, Dockery DW, Berkey CS. Body-mass index as a predictor of incident asthma in a prospective cohort of children. Pediatr Pulmonol. 2003;36(6):514-521.

12. Carroll CL, Bhandari A, Zucker A, Schramm CM. Childhood obesity increases duration of therpay during severe asthma exacerbations. Pediatric Critical Care. 2006;7(6):527-531.

13. Woolford SJ, Gebremariam A, Clark SJ, Davis MM. Incremental hospital charges associated with obesity as a secondary diagnosis in children. Obesity. 2007;15(7):1895-1901.

14. Ford ES. The epidemiology of obesity and asthma. J Allergy Clin Immunol. 2005;115(5):897-909.

15. Flaherman V, Rutherford GW. A meta-analysis of the effect of high weight on asthma. Arch Dis Child. 2006;91(4):334-339.

16. Guerra S, Wright AL, Morgan WJ, Sherrill DL, Holberg CJ, Martinez FD. Persistence of asthma symptoms during adolescence: role of obesity and age at the onset of puberty. Am J Respir Crit Care Med. 2004;170(1):78-85.

17. Gilliland FD, Berhane K, Islam T, et al. Obesity and the risk of newly diagnosed asthma in school-age children. Am J Epidemiol. 2003;158(5): 406-415.

18. Ho WC, Lin YS, Caffrey JL, et al. Higher body mass index may induce asthma among adolescents with pre-asthmatic symptoms: a prospective cohort study. BMC Public Health. 2011;11:542.

19. Burt Solorzano CM, McCartney CR. Obesity and the pubertal transition in girls and boys. Reproduction. 2010;140(3):399-410.

20. Lang JE, Hossain J, Dixon AE, et al. Does age impact the obese asthma phenotype? Chest. 2011;140(6):1524-1533.

21. Sood A, Ford ES, Camargo CA Jr. Association between leptin and asthma in adults. Thorax. 2006;61(4):300-305.

22. Tantisira KG, Litonjua AA, Weiss ST, Fuhlbrigge AL. Association of body mass with pulmonary function in the Childhood Asthma Management Program (CAMP). Thorax. 2003;58(12):1036-1041.

23. Kattan M, Kumar R, Bloomberg GR, et al. Asthma control, adiposity, and adipokines among inner-city adolescents. J Allergy Clin Immunol. 2010;125(3):584-592.

24. Chen Y, Rennie D, Cormier Y, Dosman JA. Waist circumference associated with pulmonary function in children. Pediatric Pulmonology. 2009;44(3):216-221.

25. Musaad SM, Patterson T, Ericksen M, et al. Comparison of anthropometric measures of obesity in childhood allergic asthma: central obesity is most relevant. J Allergy Clin Immunol. 2009;123(6):1321-1327.

26. Zahran HS, Bailey C, Garbe P. Vital signs: asthma prevalence, disease characteristics, and self-management education: United States, 2001-2009. MMWR. 2011;60(17):547-552.

27. Fuhlbrigge A, Peden D, Apter AJ, et al. Asthma outcomes: exacerbations. J Allergy Clin Immunol. 2012;129(Suppl 3):S34-S48.

28. Quinto KB, Zuraw BL, Poon KY, Chen W, Schatz M, Christiansen SC. The association of obesity and asthma severity and control in children. J Allergy Clin Immunol. 2011;128(5):964-969.

29. Carroll CL, Stoltz P, Raykov N, Smith SR, Zucker AR. childhood overweight increases hospital admission rates for asthma. Pediatrics. 2007;120(4):734-740.
30. Ginde AA, Santillan AA, Clark S, Camargo CA Jr. Body mass index and acute asthma severity among children presenting to the emergency department. Pediatr Allergy Immunol. 2010;21(3):480-488.

31. Goulenok C, Monchi M, Chiche JD, Mira JP, Dhainaut JF, Cariou A. Influence of overweight on ICU mortality: a prospective study. Chest. 2004;125(4):1441-1445.

32. Carroll CL, Bhandari A, Zucker AR, Schramm CM. Childhood obesity increases duration of therapy during severe asthma exacerbations. Pediatr Crit Care Med. 2006;7(6):527-531.

33. Global Initiative for Asthma, Global Strategy for Asthma Management and Prevention; 2011.

34. EPR-3. Expert Panel Report 3: guidelines for the diagnosis and management of asthma. Bethesda, MD: National Heart, Lung, and Blood Institute National Asthma Education and Prevention Program; 2007.

35. Szefler SJ, Mitchell H, Sorkness CA, et al. Management of asthma based on exhaled nitric oxide in addition to guideline-based treatment for inner-city adolescents and young adults: a randomised controlled trial. Lancet. 2008;372(9643):1065-1072.

36. Ross KR, Hart MA, Storfer-Isser A, et al. Obesity and obesity related co-morbidities in a referral population of children with asthma. Pediatr Pulmonol. 2009;44(9):877-884.

37. Ross KR, Storfer-Isser A, Hart MA, et al. Sleep-disordered breathing is associated with asthma severity in children. J Pediatr. 2012;160(5): 736-742.

38. Hakala K, Stenius-Aarniala B, Sovijarvi A. Effects of weight loss on peak flow variability, airways obstruction, and lung volumes in obese patients with asthma. Chest. 2000;118(5):1315-1321.

39. Maniscalco M, Zedda A, Faraone S, et al. Weight loss and asthma control in severely obese asthmatic females. Respir Med. 2008;102(1): 102-108.

40. Stenius-Aarniala B, Poussa T, Kvarnstrom J, Gronlund EL, Ylikahri M, Mustajoki P. Immediate and long term effects of weight reduction in obese people with asthma: randomised controlled study. BMJ. 2000; 320(7238):827-832.

41. Boulet LP, Turcotte H, Martin J, Poirier P. Effect of bariatric surgery on airway response and lung function in obese subjects with asthma. Respir Med. 2012;106(5):651-660.

42. Dhabuwala A, Cannan RJ, Stubbs RS. Improvement in co-morbidities following weight loss from gastric bypass surgery. Obes Surg. 2000; 10(5):428-435.

43. Aaron SD, Fergusson D, Dent R, Chen Y, Vandemheen KL, Dales RE. Effect of weight reduction on respiratory function and airway reactivity in obese women. Chest. 2004;125(6):2046-2052.

44. da Silva PL, de Mello MT, Cheik NC, Sanches PL, Correia FA, de Piano A, et al. Interdisciplinary therapy improves biomarkers profile and lung function in asthmatic obese adolescents. Pediatr Pulmonol. 2012;47(1):8-17.

45. Shore SA. Obesity and asthma: possible mechanisms. J Allergy Clin Immunol. 2008;121(5):1087-1093.

46. Gump A, Haughney L, Fredberg J. Relaxation of activated airway smooth muscle: relative potency of isoproterenol vs tidal stretch. J Appl Physiol. 2001;90(6):2306-2310.

47. Holguin F, Cribbs S, Fitzpatrick AM, Ingram RH Jr, Jackson AC. A deep breath bronchoconstricts obese asthmatics. J Asthma. 2010; 47(1):55-60.

48. Florez H, Castillo-Florez S, Mendez A, et al. C-reactive protein is elevated in obese patients with the metabolic syndrome. Diabetes Res Clin Pract. 2006;71(1):92-100.

49. Bahceci M, Gokalp D, Bahceci S, Tuzcu A, Atmaca S, Arikan S. The correlation between adiposity and adiponectin, tumor necrosis factor alpha, interleukin-6 and high sensitivity C-reactive protein levels. Is adipocyte size associated with inflammation in adults? J Endocrinol Invest. 2007;30(3):210-214.

50. Keaney JF Jr, Larson MG, Vasan RS, et al. Obesity and systemic oxidative stress: clinical correlates of oxidative stress in the Framingham Study. Arterioscler Thromb Vasc Biol. 2003;23(3):434-439. 
51. Bougoulia M, Triantos A, Koliakos G. Plasma interleukin-6 levels, glutathione peroxidase and isoprostane in obese women before and after weight loss. Association with cardiovascular risk factors. Hormones (Athens). 2006;5(3):192-199.

52. Fantuzzi G. Adipose tissue, adipokines, and inflammation. J Allergy Clin Immunol. 2005;115(5):911-919.

53. Michelson PH, Williams LW, Benjamin DK, Barnato AE. Obesity, inflammation, and asthma severity in childhood: data from the National Health and Nutrition Examination Survey 2001-2004. Ann Allergy Asthma Immunol. 2009;103:381-385.

54. Rastogi D, Canfield SM, Andrade A, et al. Obesity-associated asthma in children. Chest. 2012;141(4):895-905.

55. Belamarich PF, Luder E, Kattan M, et al. Do obese inner-city children with asthma have more symptoms than nonobese children with asthma? Pediatrics. 2000;106(6):1436.

56. Rodrigo GJ, Plaza V. Body mass index and response to emergency department treatment in adults with severe asthma exacerbations: a prospective cohort study. Chest. 2007;132(5):1513-1519.

57. Holguin F, Fitzpatrick A. Obesity, asthma, and oxidative stress. J Appl Physiol. 2010;108(3):754-759.

58. Johnson JB, Summer W, Cutler RG, et al. Alternate day calorie restriction improves clinical findings and reduces markers of oxidative stress and inflammation in overweight adults with moderate asthma. Free Radic Biol Med. 2007;42(5):665-674.

59. McNeill AM, Rosamond WD, Girman CJ, et al. The metabolic syndrome and 11-year risk of incident cardiovascular disease in the atherosclerosis risk in communities study. Diabetes Care. 2005;28(2):385-390.

60. Morrison JA, Friedman LA, Gray-McGuire C. Metabolic syndrome in childhood predicts adult cardiovascular disease 25 years later: the Princeton Lipid Research Clinics Follow-up Study. Pediatrics. 2007; 120(2):340-345.

61. Leone N, Courbon D, Thomas F, et al. Lung function impairment and metabolic syndrome: the critical role of abdominal obesity. Am J Respir Crit Care Med. 2009;179(6):509-516.

62. Al-Shawwa BA, Al-Huniti NH, DeMattia L, Gershan W. Asthma and insulin resistance in morbidly obese children and adolescents. JAsthma. 2007;44(6):469-473.
63. Husemoen LLN, Glumer C, Lau C, Pisinger C, Morch LS, Linneberg A Association of obesity and insulin resistance with asthma and aeroallergen sensitization. Allergy. 2008;63(5):575-582.

64. Shore SA, Terry RD, Flynt L, Xu A, Hug C. Adiponectin attenuates allergen-induced airway inflammation and hyperresponsiveness in mice. J Allergy Clin Immunol. 2006;118(2):389-395.

65. Sin DD, Man SF. Impaired lung function and serum leptin in men and women with normal body weight: a population based study. Thorax. 2003;58(8):695-698.

66. Kim KW, Shin YH, Lee KE, Kim ES, Sohn MH, Kim KE. Relationship between adipokines and manifestations of childhood asthma. Pediatr Allergy Immunol. 2008;19(6):535-540.

67. Holguin F, Rojas M, Brown LA, Fitzpatrick AM. Airway and plasma leptin and adiponectin in lean and obese asthmatics and controls J Asthma. 2011;48(3):217-223.

68. Kohler MJ, van den Heuvel CJ. Is there a clear link between overweight/ obesity and sleep disordered breathing in children? Sleep Med Rev. 2008;12(5):347-361; discussion 363-344.

69. Redline S, Tishler PV, Schluchter M, Aylor J, Clark K, Graham G. Risk factors for sleep-disordered breathing in children. Associations with obesity, race, and respiratory problems. Am J Respir Crit Care Med. 1999;159(5 Pt 1):1527-1532.

70. Van Hoorenbeeck K, Franckx H, Debode P, et al. Weight loss and sleep-disordered breathing in childhood obesity: effects on inflammation and uric acid. Obesity. 2012;20(1):172-177.

71. Verhulst SL, Franckx H, Van Gaal L, De Backer W, Desager K. the effect of weight loss on sleep-disordered breathing in obese teenagers. Obesity. 2009;17(6):1178-1183.

72. Gozal D, Kheirandish L. Oxidant stress and inflammation in the snoring child: confluent pathways to upper airway pathogenesis and end-organ morbidity. Sleep Med Rev. 2006;10(2):83-96.

73. Sulit LG, Storfer-Isser A, Rosen CL, Kirchner HL, Redline S. Associations of obesity, sleep-disordered breathing, and wheezing in children. Am J Respir Crit Care Med. 2005;171(6):659-664.
Adolescent Health, Medicine and Therapeutics

\section{Publish your work in this journal}

Adolescent Health, Medicine and Therapeutics is an international, peer-reviewed, open access journal focusing on health, pathology, and treatment issues specific to the adolescent age group. All aspects of health maintenance, preventative measures and disease treatmen interventions are addressed within the journal and practitioners from

\section{Dovepress}

all disciplines are invited to submit their work as well as healthcare researchers and patient support groups.. The manuscript management system is completely online and includes a very quick and fair peerreview system. Visit http://www.dovepress.com/testimonials.php to read real quotes from published authors. 